\title{
Primary splenic angiosarcoma diagnosed after splenectomy for spontaneous rupture
}

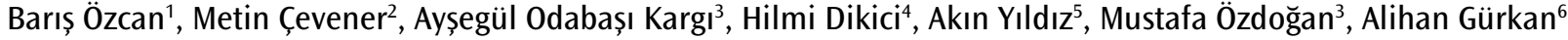

\section{ABSTRACT}

\section{Cite this paper as:}

Özcan B, Çevener M, Odabaşı

Kargı A, Dikici H, Yıldız A,

Özdoğan $M$, Gürkan A.

Primary splenic angiosarcoma

diagnosed after splenectomy

for spontaneous rupture. Turk J

Surg 2018; 34: 68-70.

'Department of General Surgery, Medstar Antalya Hospital,

Antalya, Turkey

2Department of Radiology,

Medstar Antalya Hospital,

Antalya, Turkey

${ }^{3}$ Department of Medical

Oncology, Medstar Antalya

Hospital, Antalya, Turkey

${ }^{4}$ Department of

Gastroenterology, Medstar

Antalya Hospital, Antalya, Turkey

${ }^{5}$ Department of Nuclear

Medicine, Medstar Antalya

Hospital, Antalya, Turkey

${ }^{6}$ Department of General Surgery,

Memorial Antalya Hospital,

Antalya, Turkey

This study was presented at the $21^{\text {th }}$ National Cancer Congress, 26 April 2015, Antalya, Turkey.

Address for Correspondence
Barıš Özcan
e-mail: barisozcan2004@yaho0.com
Received: 22.05 .2015
Accepted: 19.07 .2015
Available Online Date: 03.01 .2018
OCopyright 2018
by Turkish Surgical Association
Available online at
www.turkjsurg.com

Primary splenic angiosarcoma is a rare abnormality and has a bad prognosis. It has unknown pathogenesis. This abnormality is usually presented by splenic rupture. Surgery is the most promising treatm Surgery is the most accepted and accurate method for diagnosis and treatment. Surgery before rupture increases the life expectancy. A 65 -year-old woman who presented to the emergency room with abdominal pain, abdominal distension, and anemia was found to have a splenic mass and massive ascites. After getting a hemorrhagic sample from the abdomen, the patient was operated with splenic rupture prediagnosis. The spleen material was reported as splenic angiosarcoma. The staging 18F-FDG-Positron Emission Tomography-Computed Tomography did not show any metastasis. Five months later, paclitaxel treatment was initiated upon liver and bone metastasis, and the treatment still continues. Splenic angiosarcoma has a place among splenic parenchymal lesions. The splenectomy material names the diagnosis. Pathologic examination of splenectomy material is revealed certain diagnosis.

Keywords: Imaging, primary splenic angiosarcoma, spontaneous splenic rupture, splenectomy

\section{INTRODUCTION}

Primary splenic angiosarcoma is a rare lesion with an incidence rate of 0.14-0.25 cases per year per million individuals. The prognosis is poor and $30 \%$ of the cases are diagnosed on splenectomy due to spontaneous rupture $(1,2)$. It was first described by Langhans in 1879 (3). Around $75 \%$ of cases present with abdominal pain, where one-third of the cases witnesses rupture of the involved organ. Although the treatment consists of splenectomy followed by chemotherapy (sometimes combined with radiotherapy), it is known as a chemoresistant tumor.

We aimed to describe a patient with splenic rupture diagnosed to have primary splenic angiosarcoma on splenectomy.

\section{CASE PRESENTATION}

The patient was informed that she has a rare disease; her written consent was received for publication purposes. 65-year-old women patient with anemia was referred from another hospital. Multiple polyps were found in the colon, and she was transfused three units of erythrocyte suspension/RBCs within 2 days due to gastrointestinal bleeding. She presented at our emergency room with abdominal pain and distension. Her ultrasound showed a splenic mass, which was sized about $12 \times 9 \mathrm{~cm}$ in diameter with central necrosis and massive peritoneal fluid collection around the liver and spleen. Subsequently, contrast-enhanced computed tomography (CT) yielded well-defined exophytic mass with heterogeneous contrast enhancement and necrotic areas in middle spleen, which were $10 \mathrm{~cm}$ in diameter. Massive amount of perisplenic, perihepatic, and pelvic fluid was also detected (Figure 1). The sampling of this fluid showed pure blood, and patient was taken to the operating room. During laparotomy, free blood was found in the abdomen. Aproximately $10 \mathrm{~cm}$ mass was seen along posterior to hilus in spleen. Spontaneous rupture and active bleeding was found on the splenic capsule of mass (Figure 2). Total splenectomy was performed using ligasure and ties of the vascular structures and attachments. The abdominal cavity was irrigated with warm water. The patient was discharged on postoperative day 4.

The pathology showed primary angiosarcoma, which was $9 \times 5 \mathrm{~cm}$ in diameter and confined to the spleen (Figure 3,4).

As staging 18F-FDG-Positron Emission Tomography-Computed Tomography (PET-CT) showed no distant metastasis and chemotheraphy was not given (Figure 5). After 5 months, CT scan showed bone and liver metastasis, and chemotherapy (paclitaxel $80 \mathrm{mg} / \mathrm{m}^{2} /$ day; days 1,8,15, and 28) was initiated and it still continues. 


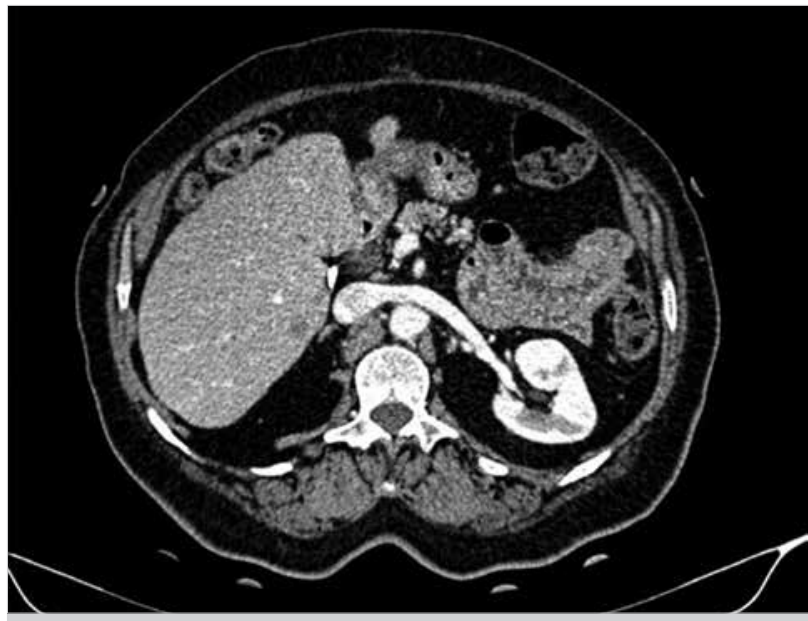

Figure 1. Contrast-enhanced CT shows an exophytic semisolid mass with contrastenhancementin the spleen. Hemoperitoneum is also seen in perisplenic and perihepatic areas

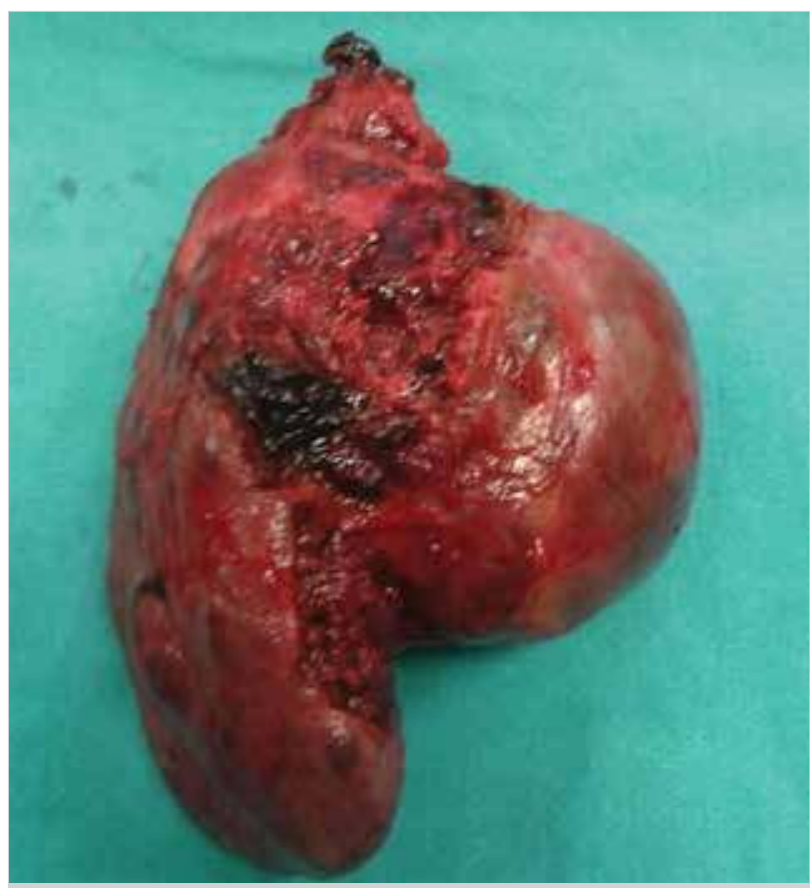

Figure 2. Macroscopic view of the surgical specimen

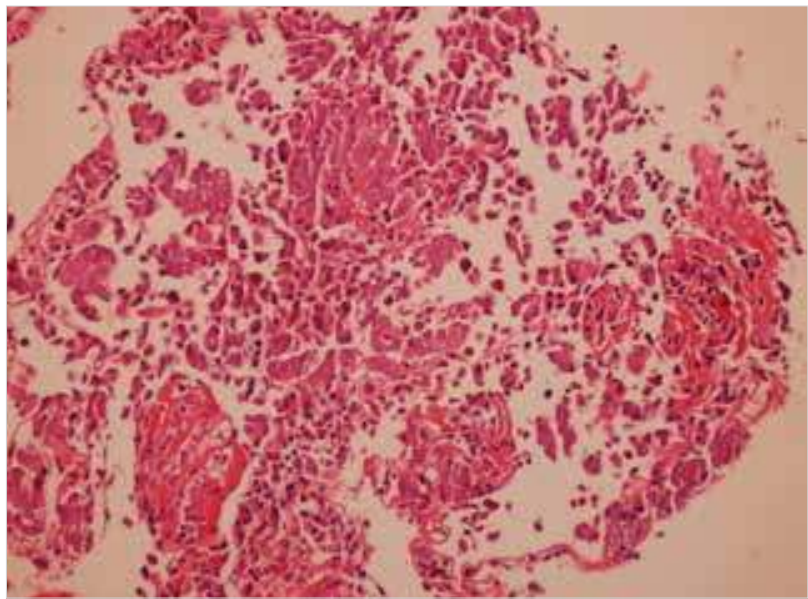

Figure 3. Angiosarcoma, spleen, H\&E 200x, and papillary and vascular channels lined by typical, hyper-chromatic cells

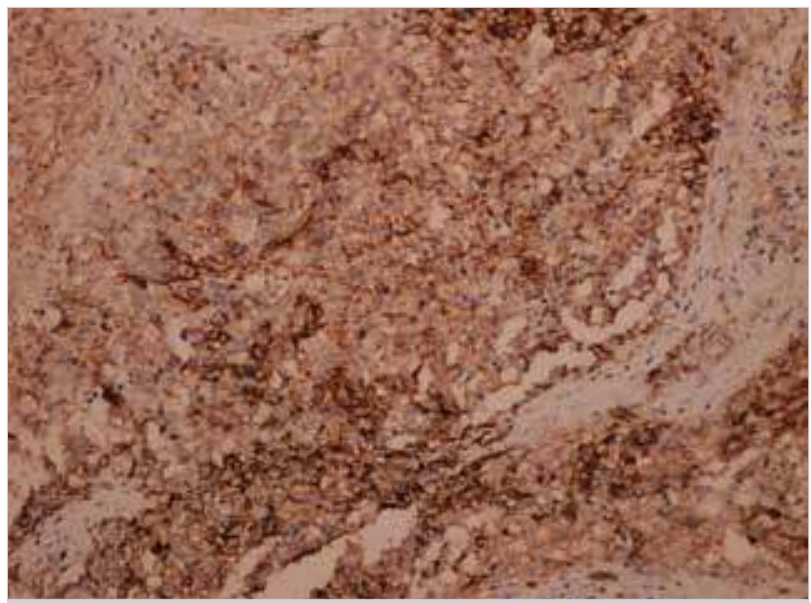

Figure 4. Cytoplasmic expression of CD31 in the tumor cells, $200 x$

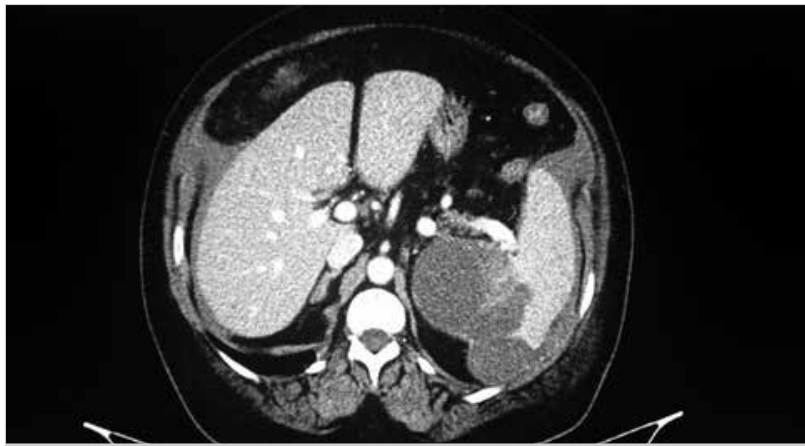

Figure 5. Follow-up contrast-enhanced abdominal CT examination shows hepatic metastasis 5 months after surgery

\section{DISCUSSION}

Primary splenic angiosarcoma is a rare and aggressive tumor (1). It is originated from mesenchymal cells located in vascular endothelium and splenic sinusoids (1). The risk of local recurrence and metastasis is high. It is more common in females, frequently after 40 years of age. Our case was a 65-year-old woman.

There is no specific screening test for diagnosis, and $80 \%$ of cases present with upper abdominal pain. However, fever, weight loss, and fatigue are seen in less than $10 \%$ of cases (1, 2 ). Splenomegaly is the dominant physical finding, which is felt as a palpable mass in left upper quadrant of body. The ratio of splenic rupture is $13 \%-32 \%$. Our patient presented with anemia and abdominal pain, and the CT scan showed abdominal hemorrhage due to splenic rupture.

Splenic angiosarcoma was first described by Langhans in 1879 (3). Jimenz-Heffernan et al. (4) reported a case presented by rectal bleeding due to rupture of the spleen into the colon. The symptoms of splenic angiosarcoma may be different; in $75 \%$ of cases, abdominal pain is the main symptom, and in one-third cases, there are symptoms of ruptured organ $(1,3)$. Anemia, leucopenia, elevation of $\mathrm{LDH}$, and thrombocytopenia are frequently reported. Anemia is secondary to destruction of erythrocyte surface and can be severe due to hemolysis (5). Sometimes, thrombocytopenia is the first sign of the disease (5).

Splenic angiosarcoma has poor prognosis, and only $20 \%$ of cases have a survival longer than six months $(2,4)$. In most 
cases, survival is limited to 30-90 days after surgery $(1,2)$. Intraabdominal bleeding is a poor prognostic factor (1). The metastasis rate is between $69 \%$ and $100 \%$ and is mostly seen in liver, bone, and bone marrow $(1,2)$. In our patient, the outcome was similar and metastasis in the liver and bone was detected in 4-5 month after surgery. Preoperative biopsy as a diagnostic tool is dangerous considering bleeding and seeding. Preoperative CT is helpful for diagnosis and detection of complications in $60 \%$ of cases (6). It shows splenic enlargement or mass and punctate calcification $n$ the spleen (7). Even in our case, CT helped identify a mass and the rupture of the spleen.

Splenectomy is the option for localized disease $(1,8)$. The median survival for splenic angiosarcoma is 5 months. In literature, there are cases responding to weekly paclitaxel treatment $(9,10)$. The PET CT scan after surgery did not show any sign of metastasis. The patient was followed up for 4-5 months and after this period, metastasis to the liver and bone was found. Therefore, paclitaxel treatment with $80 \mathrm{mg} /$ day on days $1,8,15$, and 28 was initiated. The patient continues to be on the same treatment.

\section{CONCLUSION}

A spontaneous splenic mass rupture can be primary splenic angiosarcoma. Because of the aggressive progress and mortality of the disease, it should be considered that splenectomy without rupture may prolong patient survival significantly.

Informed Consent: Written informed consent was obtained from patient who participated in this study.

Peer-review: Externally peer-reviewed.

Author Contributions: Concept - B.Ö., A.G.; Design - B.Ö.; Supervision - A.Y., A.G.; Resource - M.Ç., B.Ö.; Materials - H.D., B.Ö.; Data Collection and/or Processing - B.Ö., M.Ç., A.O.K.; Analysis and/or Interpretation -
B.Ö., A.Y., M.Ç.; Literature Search - B.Ö., A.O.K.; Writing Manuscript - B.Ö., A.G., A.O.K.; Critical Reviews - A.Y., M.Ö.

Conflict of Interest: No conflict of interest was declared by the authors.

Financial Disclosure: The authors declared that this study has received no financial support.

\section{REFERENCES}

1. Falk S, Krishnan J, Meis JM. Primary angiosarcoma of the spleen. A clinico pathologic study of 40 cases. Am J Surg Pathol 1993; 17: 959-970. [CrossRef]

2. Neuhauser TS, Derringer GA, Thompson LD, Fanburg-Smith JC, Miettinen $M$, Saaristo A, et al. Splenic angiosarcoma: a clinico pathologic and immuno phenotypic study of 28 cases. Mod Pathol 2000; 13: 978-987. [CrossRef]

3. Langhans T. Pulsating cavernous neoplasm of the spleen with metastatic nodules to the liver. Virchows Arch Pathol Anat. 1879; 75: 273-291. [CrossRef]

4. Jiménez-Heffernan JA, Hardisson D, Prieto-Nieto MI, Burgos E. Ruptured primary splenic angiosarcoma into the colon: Presentati as anal bleeding. Acta Gastroenterol Belg 1999; 62: 248-251.

5. Raffel S, Hildebrandt B, Grieser C, Pahl S, Sturm I. Thrombocytopenia as first manifestation of splenic angiosarcoma. Ann Hematol 2010; 89: 109-110. [CrossRef]

6. Thompson WM, Levy AD, Aguilera NS, Gorospe L, Abbott RM. Angiosarcoma of the spleen: imaging characteristics in 12 patients. Radiology 2005; 235: 106-115. [CrossRef]

7. F. Ferrozzi, D. Bova, F. Draghi, and G. Garlaschi. CT findings in primary vascular tumors of the spleen. American Journal of Roentgenology 1996; 166: 1097-1101. [CrossRef]

8. Duan $Y$, Jiang $Y, W u ~ C$, and Zhu F. Spontaneous rupture of primary splenic angiosarcoma: a case report and literature review. World Journal of Surgical Oncology 2013; 11: 53-57. [CrossRef]

9. Ferreira BP, Rodler ET, Loggers ET, Pollack SM, Jones RL. Systemic therapy in primary angiosarcoma of the spleen. Rare Tumors 2012: 4; 55-59 [CrossRef]

10. Italiano A, Cioffi A, Penel N, Levra MG, Delcambre C, Kalbacher E, et al. Comparison of doxorubicin and weekly paclitaxel efficacy in metastatic angiosarcoma. Cancer 2012; 118: 3330-3336. [CrossRef] 